\title{
LA RESPONSABILIDAD DE LOS ADMINISTRADORES EN EL EJERCICIO DE SUS FUNCIONES SOCIALES
}

\author{
SONIA CALAZA LÓPEZ ${ }^{1}$
}

RESUMEN: Este trabajo trata acerca de la responsabilidad que los administradores de las empresas tienen frente a la sociedad, frente a los accionistas y frente a los acreedores sociales; como asimismo del daño que causen por actos contrarios a la Ley o a los Estatutos y por los realizados sin la diligencia con la que deben desempeñar el cargo. Al respecto se revisan los distintos modos de bacer efectiva esa responsabilidad y sus distintos órdenes normativos. En fin, el modo en que habiéndose ejercitado acciones en contra de los administradores, pueda la misma sociedad renunciar a ello, transar sobre ello; y la oposición que pudiera surgir de ese acuerdo.

Palabras clave: Responsabilidad - Responsabilidad de administradores - Conducta imprudente o dolosa de administradores - Acción de responsabilidad - Normas sobre responsabilidad.

ABSTRACT: This paper is about the liability that managers bave towards its company, as well as shareholders and company creditors. It deals with damages caused by acts contrary to Law or company statutes, and for negligent conduct. In this regard, several ways to make that liability effective are reviewed. The different regulatory ordinances are also examined. Briefly, the way in which, having exercised actions against mamangers, the company may disclaim and settle about it, and the opposition that might arise against such agreement.

Key words: Liability - Officer's liability - Officer's imprudent or willful misconduct - Liability action - Liability regulations.

SUMARIO: 1. Introducción. 2. Acción social de responsabilidad. 3. Acción individual de responsabilidad. 4. Conflicto de intereses. 5. Regulación legal interna. 6. Códigos éticos. 7. El acuerdo de renuncia o transacción del ejercicio de una acción social de responsabilidad frente a los administradores $y$ oposición.

Profesora. Doctora de Derecho Procesal de la Universidad Nacional de Educación a Distancia (UNED), España. Artículo recibido el 30 de marzo de 2004. Aceptado por el Comité Editorial el 12 de agosto de 2005. 


\section{INTRODUCCIÓN}

Los administradores, según dispone el artículo $127.1^{\circ}$ de la Ley de Sociedades Anónimas, desempeñarán su cargo con la diligencia de un "ordenado empresario" y de un "representante leal".

La razón de ser de este deber de diligencia ${ }^{2}$ impuesto, de manera expresa, a los administradores, reside en que conforman un órgano destinado al desarrollo del objeto social y a la ejecución de la voluntad de la persona jurídica, respecto de cuya gestión, administración y representación, habrán de responder, en los supuestos en los que resulte fehacientemente demostrada la existencia de un nexo de causalidad entre el daño causado y la culpa o negligencia de las actuaciones de los mismos ${ }^{3}$.

Los administradores responderán, frente a la sociedad, frente a los accionistas y frente a los acreedores sociales, del daño que causen por actos contrarios a la Ley o a los Estatutos y por los realizados sin la diligencia con la que deben desempeñar el cargo (art. 133. $1^{\circ}$ LSA).

La regulación normativa de anónimas introduce, asimismo, en el apartado segundo del mismo artículo, una plausible novedad, en la materia referida a la solidaridad en la responsabilidad puesto que, tan solo responderán solidariamente todos los miembros del órgano de administración que realizó el acto o adoptó el acuerdo lesivo ${ }^{4}$, cuando no resulte probada, por parte de uno o varios de los administradores integrantes del mencionado órgano, la falta de intervención en la adopción y correlativa ejecución del acto o acuerdo perjudicial, el desconocimiento de su existencia o, en su caso, la prueba suficientemente demostrativa de que hi-

2 Los parámetros que debe observar el administrador en el desempeño de su actividad, conforme al deber de diligencia prescrito por el art. 127 de la LSA, se reconducen, según FONT RIBAS, A, a dos hechos o comportamientos de carácter positivo y a otros dos de carácter negativo. Desde el punto de vista posirivo, el administrador debe actuar con la diligencia que cabe exigir a un profesional y con la lealtad propia de aquel que recibe un encargo para la gestión de intereses ajenos. Desde el ángulo negativo, debe abstenerse de divulgar información de carácter confidencial $y$, asimismo, de entrar en concurrencia o en conflicto con la sociedad y empresa que administra, "La asegurabilidad de la responsabilidad de los administradores de sociedades", en La responsabilidad de los administradores de las sociedades de capital. Aspectos civiles, penales y fiscales, Tecnos, Madrid, 1999, p. 104 y ss.

3 Vid, más ampliamente, AlCALÁ Díaz, M.A.: "Acción individual de responsabilidad frente a los administradores", $\operatorname{RdS} \mathrm{N}^{\circ} 1,1993$, p. 171 y ss.

Así, pues, la STS de 29 de diciembre de 2000 (r. 354) se ha pronunciado, en su cuarto Fundamento de Derecho, en los siguientes términos: "en la actualidad, prácticamente, dentro de la praxis judicial, se está casi en el umbral de la llamada responsabilidad objetiva o por riesgo, porque, en cuanto se produzca el daño y se acredite el nexo causal, la responsabilidad del Administrador o el Consejero, será inevitable; este art.133, en su párrafo $2^{\circ}$, impone la responsabilidad solidaria de todos los administradores/consejeros que realizaron el acto o adoptaron el acuerdo". 
cieron todo lo conveniente para evitar el daño o, al menos, que se opusieron expresamente a aquel ${ }^{5}$.

La responsabilidad será exigible, por tanto, a aquellos administradores a quienes quepa imputar la conducta imprudente o dolosa y no al órgano colegiado del que forman parte, sin perjuicio de que las consecuencias patrimoniales puedan imputarse a la persona jurídica de la que aquellos sean representantes ${ }^{6}$.

La responsabilidad no quedará exonerada por la circunstancia de que el acto o el acuerdo lesivo haya sido adoptado, autorizado o ratificado por la Junta General (art. 133. $3^{\circ}$ LSA).

Sin perjuicio de la responsabilidad civil de los administradores, que abordaremos, siquiera sea brevemente, en los epígrafes que siguen, parece oportuno indicar, en este momento, que el Código Penal tipifica, en su artículo 295, el delito de administración social fraudulenta, que supone, a juicio de la doctrina que se ha ocupado del estudio y análisis de los delitos societarios ${ }^{7}$, una importante novedad en la intervención del Derecho Penal en el ámbito de las relaciones específicas del Derecho privado, más concretamente en el funcionamiento de las sociedades mercantiles.

Así, pues, los administradores de hecho o de derecho o los socios de cualquier sociedad constituida o en formación, que en beneficio propio o de un tercero, con abuso de las funciones propias de su cargo, dispongan fraudulentamente de los bienes de la sociedad o contraigan obligaciones a cargo de esta causando directamente un perjuicio económicamente evaluable a sus socios, depositarios, cuentapartícipes o titulares de los bienes, valores o capital que administren, serán castigados con la pena de prisión de seis meses a cuatro años, o multa del tanto al triplo del beneficio obtenido.

De manera complementaria a la acción de impugnación de los acuerdos sociales ${ }^{8}$, adoptados en el seno del Consejo de Administración de las

5 La nueva Ley, como se ha encargado de señalar BOLÁs ALFONSO, J.: "es más rigurosa en materia de responsabilidad de los administradores, por cuanto que esta, a diferencia del antiguo art. 79 LSA de 1951, ya no se hace depender de la concurrencia de malicia, abuso de facultades o negligencia grave", en "La adaptación de las sociedades de capital a la vigente normativa: la triple vertiente de la obligación de adaptación. Problemas prácticos", RJN, 1992, p. 41.

6 Vid. al respecto, Alonso Ureba, A.: "Presupuestos de la responsabilidad social de los administradores de una Sociedad Anónima", RDM N 198, 1992, p. 654; PULGAR EzQUERRA, J.: "El régimen especial de responsabilidad de los administradores de una Sociedad Anónima por incumplimiento de la obligación legal de adaptación estatutaria", RdS $N^{\circ} 2,1994$, p. 210.

7 Vid, en este sentido, FERRÉ OLIVÉ, J.C.: "La administración social fraudulenta (artículo 295 del Código Penal)", en La responsabilidad de los administradores de las sociedades de capital. Aspectos civiles, penales y fiscales, Tecnos, Madrid, 1999, p. 128 y ss.

8 Para un estudio pormenorizado y de conjunto a propósito de la impugnación de los acuerdos sociales, se remite al lector a las obras de la autora del presente trabajo de 
sociedades anónimas, podrán los sujetos jurídicamente legitimados al efecto, interponer, previo acuerdo válidamente adoptado en la Junta General, una acción social de responsabilidad o, en su caso, una acción individual de responsabilidad contra los administradores ${ }^{9}$, por la falta de diligencia debida o por la mala fe derivada de sus actuaciones y de sus acuerdos $^{10}$, ante el Juez del domicilio social ${ }^{11}$.

\section{ACCIÓN SOCIAL DE RESPONSABILIDAD}

La acción social de responsabilidad contra los administradores se entablará por la sociedad, previo acuerdo de la Junta General, que puede ser adoptado aunque no conste en el orden del día (ex, art. 134. $1^{\circ}$ ).

La acción social de responsabilidad procederá siempre y cuando resulten dañados los intereses sociales como consecuencia de la realización, por parte de los administradores, de una conducta, que podría considerarse, de un lado, transgresora de la Ley o de los estatutos, o, en su caso, de otro, negligente.

Ahora bien, la acción social de responsabilidad puede provenir, tanto de la comisión por acción ${ }^{12}$, negligente o culposa, de un acto que profiera un perjuicio a la sociedad, como de la comisión por omisión ${ }^{13}$, con idénticas connotaciones en la voluntad del administrador, siempre que igualmente profiera un daño a los legítimos intereses del ente social.

En este sentido, constituye un supuesto típico de la acción de responsabilidad, el abandono de hecho y consciente, por parte del administrador, de una sociedad anónima, a la que deja en una situación de paralización de sus órganos sociales, cuando la LSA, en su artículo $260.3^{\circ}$,

investigación, CALAZA LÓPEZ, S.: El proceso de impugnación de acuerdos sociales de sociedades anónimas y cooperativas, Ed. CEURA, Madrid, 2003 y El proceso de formación de la voluntad social de las sociedades anónimas y cooperativas: vicios de contenido y de procedimiento, Dykinson, Madrid, 2003.

y Se trata, como se ha encargado de señalar Tapia Hermida, A. J.: de acciones distintas que se basan en diferentes presupuestos, en "Los administradores de Sociedades Anónimas que incumplan los deberes que la Ley les impone en orden a procurar la disolución (art, 262. $5^{a}$ LSA), son responsables de la totalidad de las obligaciones sociales de la Compañía", RDBB N ${ }^{\circ} 68$, octubre-diciembre, 1997, p. 1415.

10 Para un estudio detallado, se remite al lector al estudio de MAgro Servet, V.: "La responsabilidad civil de los administradores de Sociedades (especial referencia a la prescripción de la acción para exigirles responsabilidad civil)", $\mathrm{AC} \mathrm{N}^{\circ} 48$, diciembre-enero, 1999-2000, p. 1627 a 1650.

11 Vid., STS de 13 de mayo de 1995 (JAC N ${ }^{\circ}$ 814).

12 Vid., la STS de 9 de abril de 1997 (JAC N ${ }^{\circ} 723$ ), que califica de "negligente" la conducta del administrador que, en contra de lo pactado, realiza una operación de alto riesgo, pues dicha conducta no se ajusta al deber de todo comerciante de obrar conforme a la buena fe.

13. Vid., al respecto, las SSTS de 26 de julio de 1994 (JAC N ${ }^{\circ} 1293$ ) y de 25 de sepriembre de 1996 (JAC N 21). 
le exige precisamente responsabilidad por no promover la liquidación ${ }^{14}$ y disolución de dicha sociedad ${ }^{15}$, incursa en imposibilidad manifiesta de realizar su fin social ${ }^{16}$, máxime cuando, igualmente, le corresponda la obligación de convocar la Junta General, incluso para pronunciarse sobre su continuidad o el nombramiento de otro administrador, siempre que asimismo, haya transcurrido el plazo por el que fue nombrado ${ }^{17}$.

La persona perjudicada por la realización de las conductas descritas será la propia sociedad, razón por la que la acción social de responsabilidad entablada por dicha sociedad habrá de ser previamente adoptada, a través de un acuerdo social ${ }^{18}$, por los accionistas, en la Junta General.

Los accionistas que representen, cuando menos, un cinco por ciento del capital social podrán, asimismo, solicitar la convocatoria de la Junta General para que decida sobre el ejercicio de la acción de responsabilidad y, paralelamente, entablar de manera conjunta dicha acción de responsabilidad en defensa del interés social cuando los administradores no convocasen la Junta General solicitada con esta finalidad, cuando la sociedad no la entablare en el plazo de un mes, contado desde la fecha de adopción del correspondiente acuerdo, o bien cuando este hubiere sido contrario a la exigencia de responsabilidad (ex. art. 134. $4^{\circ}$ ).

Los acreedores de la sociedad ${ }^{19}$ también podrán ejercitar la acción social de responsabilidad ${ }^{20}$, contra los administradores, cuando dicha acción no haya sido ejercitada por la sociedad o sus accionistas, siempre

14 La no liquidación en forma legal del parrimonio social cuando la sociedad se encuentra en una situación de insolvencia, según la STS de 22 de abril de 1994 (JAC No 866) es susceptible de inferir un daño directo por configurar una negligencia grave de los administradores, en el incumplimiento de sus deberes legales.

15 Para un estudio pormenorizado en relación con la responsabilidad de los administradores por disolución de la sociedad según las distintas causas que puedan operar esa disolución, se remite al lector al estudio de Bercovitz Rodríguez-Cano, A., "Régimen general de la responsabilidad civil de los administradores de las sociedades de capital", en La responsabilidad de los administradores de las sociedades de capital. Aspectos civiles, penales y fiscales, Tecnos, Madrid, 1999, p. 24 y ss.

16 Ahora bien, aun cuando la acción social de responsabilidad podrá ser ejercitada durante el período de liquidación, tanto por la sociedad como por los accionistas y acreedores, en modo alguno, según han señalado Bueyo Díez Jalón, M., Collado Lugo, A. y PAloMO BALDA, E., estarán facultados los liquidadores para suplir la exigencia del acuerdo de la Junta, Responsabilidad de los administradores. Levantamiento del velo, Dossier Práctico Francis Lefebvre, Madrid, 2000, p. 43.

17 Vid., en este sentido, la SAP de Guipúzcoa, de 30 de junio de 2000 , r. 1469 y la STS de 15 de marzo de 2002 (r. 2846).

18 Vid., STS de 1 de diciembre de 1993, JAC $\mathrm{N}^{\circ} 362$.

19 La responsabilidad de los administradores frente a los acreedores sociales deriva, precisamente, según la STS de 22 de junio de $1995, \mathrm{AC} \mathrm{N}^{\circ} 38$, de la omisión de la diligencia de un ordenado comerciante, que deben observar los administradores en su actuación, que directamente lesiona los intereses de los acreedores.

20 La STS de 18 de marzo de 1999 (r. 2381) ha estimado, incluso, la procedencia de responsabilidad social de los administradores por las obligaciones contraídas con acreedores de buena fe aun por acto no comprendido en el objeto social. 
que el patrimonio social resulte insuficiente para la satisfacción de sus créditos (ex, art. $143.5^{\circ}$ ).

La acción de responsabilidad prescribirá, conforme reiterada jurisprudencia ${ }^{21}$, en el plazo cuatrienal previsto en el artículo 949 del Código de Comercio, conforme al cual la acción contra los socios gerentes y administradores de las compañías o sociedades terminará a los cuatro años, a contar desde que por cualquier motivo cesaren en el ejercicio de la administración.

\section{ACCIÓN INDIVIDUAL DE RESPONSABILIDAD}

No obstante lo dispuesto en los preceptos referidos a la responsabilidad de los administradores y a la acción social de responsabilidad, quedan a salvo las acciones de indemnización que puedan corresponder a los socios y a terceros por actos de los administradores que lesionen directamente sus intereses (ex. art. 135).

La acción individual de responsabilidad procederá ${ }^{22}$, por tanto, siempre y cuando resulten dañados los intereses individuales, personales, directos o primarios de los socios y terceros ${ }^{23}$.

La procedencia de la petición de responsabilidad personal de los administradores, entablada a través de la acción individual de responsabilidad, exige la concurrencia necesaria de los presupuestos siguientes ${ }^{24}$ : en primer lugar, la producción del daño ocasionado en los intereses de los socios o de los terceros, que ha de ser estimable; en segundo lugar, la

21 En este sentido, las SSTS de 22 de junio de 1995 (r. 5179), de 2 de julio de 1999 (r. 4900), de 20 de julio de 2001 (r. 6863) y de 26 de octubre de 2001 (r. 8134); Vid, asimismo, la SAP de Albacete, de 24 de noviembre de 2000, r. 564 y la SAP de Guadalajara, de 1 de febrero de 2001, r. 1157.

22 La acción individual de responsabilidad cabe, según ha quedado expresamente sentado en el tercer Fundamento de Derecho de la STS de 14 de mayo de 1996 (r. 3907), "cuando se lesionan directamente intereses patrimoniales por consecuencia del actuar doloso del administrador o cuando ha incurrido en abuso de facultades o negligencias que ha de tener intensidad grave, $y$, a su vez, si ha llevado a cabo actuaciones que expresan incumplimiento de la Ley o de la escritura fundacional".

23 Conviene en este momento recordar, con MARín CORREA, J.M.: que "los trabajadores son terceros, respecto de la relación entre la sociedad y sus administradores, razón por la cual no tendrán a su favor la "acción social" del artículo 134; pero sí podrán actuar sus derechos al amparo formal de los artículos 133 y 135 , frente a los administradores", en "La responsabilidad de los administradores de sociedades de capital", Estudios de Derecho Judicial No 24, CGPJ-CGN, Madrid, 2000, pp. 305 y 306.

21. En este sentido, entre múltiples otras, las SSTS de 12 de abril de 1989 (r. 3007), de 26 de noviembre de 1990 (r. 9050), de 12 de junio de 1995 (r. 4739), de 28 de febrero de 1996 (JAC N 408), de 31 de julio de 1996 (JAC No 922 y r. 6078), de

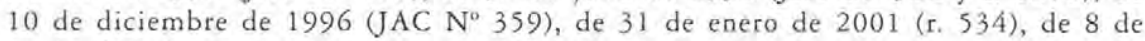
noviembre de 2001 (r. 9291) y SAP de Vizcaya (Sección 4*), de 3 de abril de 2001 (r. 1062). 
concreción de la procedencia del daño, que reside en el abuso de facultades, en la malicia o, en su caso, en la negligencia de los administradores $y$, finalmente, la acreditación de la existencia de un nexo de causalidad entre la conducta ilícita y el daño.

La acción individual de responsabilidad viene, asimismo, caracterizada por una serie de connotaciones de las que se ha venido ocupando con gran rigor nuestra más reciente doctrina jurisprudencial.

Así, pues, la acción individual de responsabilidad es, ante todo, una acción indemnizatoria y, dado que la LSA, en la redacción del precepto que la regula, utiliza una oración adversativa ("no obstante lo dispuesto en los preceptos anteriores"), fácilmente podría colegirse, en primer lugar, que dicha acción podría corresponder a los socios o terceros, con total independencia de que hubiere procedido o no la acción social de responsabilidad $^{25}$.

La legitimación activa para entablar una acción individual de responsabilidad corresponderá, en segundo lugar, según se desprende del precepto 135, a los socios y a los terceros. Sin embargo, la legitimación para entablar la acción social de responsabilidad corresponde, como es sabido, a los accionistas y a los acreedores. Ante esta divergencia en la literalidad de la LSA cabría preguntarse, si el acreedor ha de ser considerado como un tercero o no y, en función de la discriminación positiva o negativa que se obtenga como resultado de esta delimitación, si, asimismo, tiene legitimación para entablar la acción individual de responsabilidad o, por el contrario, carece de ella.

La tesis jurisprudencial ${ }^{26}$ argüida en relación con esta cuestión ha sido clara y, en este sentido, ha estimado que el acreedor es tercero cuando no está incardinado en el ente social, pues la responsabilidad de los administradores frente a los terceros reviste naturaleza extracontractual, debido a la circunstancia, expresamente comentada por la jurispruden$\mathrm{cia}^{27}$, de que no existe vínculo contractual relacionante y sí solo el genérico, contenido en el principio naeminen laedere, tratándose de responsabilidad personal de los administradores y no de la sociedad.

Sin embargo, el acreedor no es tercero cuando está ligado con la sociedad a través del contrato del cual emana su crédito.

25 En este sentido, la STS de 28 de junio de 2000 (r. 5912), que, asimismo, insiste en que "el foco de la discinción con la acción social de esta acción individual de responsabilidad radica en que el acto atacado transgreda intereses individuales del perjudicado, los socios - terceros; responsabilidad, pues, claramente extracontractual con la exigencia de los presupuestos del art. 1902 CC y entre ellos, el indispensable nexo causal". (r. 1683), de 30 de marzo de 2001 (r. 6639) y de 19 de noviembre de 2001 (r. 355), que afirman positivamente la legitimación de los acreedores sociales. SSTS de 11 de octubre de 1991 (r. 6909) y de 21 de mayo de 1992 (r. 4274). 
Así, pues, el acreedor estará legitimado para ejercitar la acción individual de responsabilidad no en cuanto actúe como acreedor, sino en cuanto, sin perjuicio de ser acreedor, sea tercero; en definitiva, cuando el perjuicio que se le irrogue por parte del acto del administrador o consejero no sea en su crédito en concreto, sino en el resto de su patrimonio.

La acción individual de responsabilidad, finalmente, participa, según ha advertido la jurisprudencia del $\mathrm{TS}^{28}$, de la naturaleza de la de la culpa extracontractual, pues se inspira en el principio general de "no causar daño a nadie" y, por tanto, no bastará una mera relación entre el administrador y la sociedad, sino que será preciso constatar y verificar la relación del administrador con otras personas ajenas a la relación societaria, debiendo, en todo caso, acreditarse la existencia de un nexo de causalidad entre acto o acuerdo ilícitos y el daño producido ${ }^{29}$.

La carga de la prueba que, necesariamente, habrá de recaer, de un lado, sobre la acción u omisión dolosa o culposa del administrador y, de otro, sobre el nexo de causalidad entre dicha acción u omisión y el resultado dañoso ocasionado incumbe, según reiterada doctrina jurisprudencial $^{30}$ en este sentido, al demandante.

La LSA no se refiere, en su art. 135, a la actividad continuada de la Administración, sino concretamente a sus actos o acuerdos lesivos, pues la interpretación jurisprudencial ${ }^{31}$ de la expresión directamente que contiene la norma lleva a incluir en su ámbito, tan solo los supuestos en los que el daño se causa al socio individualmente considerado y no a través del que previamente se pueda producir a la sociedad.

\section{CONFLicto DE INTERESES}

La actuación negligente o culposa de los administradores no viene exclusivamente determinada por la contravención de los acuerdos que adopten con la Ley, los estatutos o los intereses sociales ${ }^{32}$ sino que, asi-

28 SSTS de 3 de abril de 1990, r. 2660, de 28 de febrero de 1996, r. 1608 y de 17 de julio de 2001 , r. 5435.

29 Vid., en relación con la necesaria acreditación del nexo causal entre la conducta y el daño, las SSTS de 30 de enero de 2001 (r. 1683) y de 11 de junio de 2001 (r. 5673) y la SAP de Toledo (Sección 1"), de 17 de enero de 2001 (r. 813). Vid, entre otras, las SSTS de 21 de septiembre de 1999 (r. 7230), de 18 de enero de 2000 (r. 69), de 28 de junio de 2000 (r. 5912) y de 25 de febrero de 2002 (r. 1908).

31 Vid. STS de 4 de noviembre de 1991 (r. 8143) y SAP de Murcia (Sección 4"), de 29 de enero de 2001 (r. 926).

32 Los administradores, tal y como acertadamente han manifestado ROJO, A. y BELTRÁN, E., "ejercen un positivo influjo sobre la Junta General de accionistas, cuyo orden del día redactan, y, por esta razón, a ellos se sanciona por el incumplimiento de una obligación legal cuyo cumplimiento, sin embargo, incumbe a la Sociedad", en "El capital social mínimo. Consideraciones de política y de técnica legislativas", RDM No 187-188, 1988, p. 172 . 
mismo, aquellos sujetos incurren en la falta de responsabilidad debida cuando, con carácter permanente o de manera ocasional, se encuentren en una posición de conflicto de intereses y, en dichas situaciones de competencia con la sociedad, no superpongan el interés común de los socios, con manifiesta inobservancia del deber de fidelidad, al suyo propio ${ }^{33}$.

El artículo $132.2^{\circ}$ de la LSA dispone que, los administradores que lo fueren de otra sociedad competidora y las personas que bajo cualquier forma tengan intereses opuestos a los de la sociedad cesarán en su cargo a petición de cualquier socio y por acuerdo de la Junta General.

Ello no obstante, el aparente rigor de esta declaración de intenciones queda, a juicio de la doctrina ${ }^{34}$, desvirtuado debido a que la resolución de la colisión de intereses depende, de un lado, de la denuncia social y, de otro, del posterior acuerdo de la Junta, cuando, en verdad, la solución más apropiada habría sido la de una regulación específica y expresa a propósito del control judicial de los acuerdos sociales adoptados por una mayoría de administradores, que se encontrasen en una situación de conflicto de intereses con la sociedad.

Ante la ausencia de regulación legal expresa de la impugnación de acuerdos adoptados bajo una esfera de eventual conflicto de intereses, entre el administrador o los administradores y la sociedad ${ }^{35}$, a diferencia de lo que acontece en la regulación italiana ${ }^{36}$, parece lo más razonable, como así lo ha suscrito la parte de la doctrina que se ha ocupado del tema, entender aplicable el tercer supuesto de los motivos de impugnación tasados en los arts. $115.1^{\circ} \mathrm{LSA}$ y $31.1^{\circ} \mathrm{LC}$ (referidos a los acuerdos lesivos de los intereses sociales, en beneficio de uno o varios accionistas o terceros) y, por tanto, tachar de anulable el acuerdo adoptado con una

33. En este sentido, Rodríguez Artigas, F. "El deber de diligencia", en El Gobierno de las Sociedades Cotizadas, Ed. Marcial Pons, Madrid-Barcelona, 1999, p. 423.

34 Velasco SAN Pedro, L.A.: "La información en el Consejo de Administración: derechos y deberes del Consejo y de los Consejeros", en El gobicrno de las sociedades cotizadas, Marcial Pons, Madrid-Barcelona, 1999, p. 359.

35 En favor del establecimiento de mecanismos de control que afronten y solventen las situaciones de conflicto de interés, para fomentar el mejor gobierno de las compañías que recurren a los mercados de capitales, se posiciona Monje Gil, A., en su detallado estudio sobre la "Comisión especial para el estudio de un Código ético de los Consejos de Administración de las Sociedades", en "El Gobierno de las Sociedades", RDM N ${ }^{\circ} 228$, 1998, p. 761.

36 Para un estudio pormenorizado a propósito del conflicto de intereses entre el administrador y la sociedad, en la doctrina italiana, se remite al lector a los trabajos de PrEITE, F.: "Sull'ammissibilità dell'impugnativa delle deliberazioni del Consiglio di Amministrazione delle Società per azioni", Rivista di Diritto Civile, 1967, II, pp. 53 y ss; SPADA, P.; "L'amministrazione della società per azioni tra interesse sociale ed interesse di grupo", Rivista di Diritto Civile No 35-1, 1989, pp. 244 y ss; ABBADESSA, P.: "Gli organi di gestioni nella Società per azioni: riflessioni critiche", en $/ /$ diritto delle società per azioni: problemi, esperienza, progetti a cura di Pietro Abbadessa e Angel Rojo, Dott. A. Giuffrè Editore, Milano, 1993, pp. 293 y ss.; DI SABATO, F, Manuale delle società, UTET, Torino, 1999. 
mayoría de votos, entre los que han resultado especialmente relevantes, los correspondientes a los administradores que, en interés propio o de terceros, causaren una lesión al interés social, por encontrarse este en pugna con el que efectivamente han satisfecho ${ }^{37}$.

Ahora bien, tal y como ha ponderado la doctrina, el atinado desarrollo del "interés social", exigido a los administradores en el desempeño de sus funciones, no resulta coincidente con el que, asimismo, deben observar los accionistas en el ejercicio de sus derechos, puesto que la "concepción monista" del interés social, en tanto que interés común de los socios, ha sido objeto, en el ámbito de actuación de los administradores, de una superación en favor de la "concepción pluralista" que obliga a estos últimos, no solo a respetar el interés del capital de los accionistas, sino incluso, el de los trabajadores y el propio interés general, introduciendo en el proceso de decisión, aspectos político-sociales, además de los estrictamente empresariales ${ }^{38}$.

\section{REGULACIÓN LEGAL INTERNA}

Como es sabido, la falta de coincidencia, en una misma personalidad física o jurídica, de los miembros que conforman el órgano de representación y gestión de las sociedades, con los miembros propietarios de las acciones que integran el órgano de gobierno de las mismas, así como la tensión existente entre uno y otro órgano, unido a la falta de regulación legal específica, respecto a las relaciones de interdependencia recíproca y el régimen de sanción aplicable a las infracciones derivadas de las disfunciones surgidas, como consecuencia de las relaciones entre estos órganos sociales ha hecho correr innumerables ríos de tinta.

Si bien, en línea de principio, habría de ser a los miembros titulares de la propiedad del capital social a quienes debiera concederse el dominio y control societario, lo cierto es que, en las grandes sociedades, asumen estos privilegios los miembros del Consejo de Administración.

La regulación del régimen interno del Consejo de Administración corresponde, en primer término, a los accionistas, mediante la elaboración y posterior aprobación de los estatutos sociales ${ }^{39}$ y, en defecto de previsión estatutaria, al propio Consejo de Administración, que, en aplicación de lo establecido en loș artículos $141.1^{\circ}$ LSA y $124.2^{\circ}$ Reglamento

\footnotetext{
37 Vid. al respecto, Alcaló Díaz, M. A.: "El deber de fidelidad de los administradores: el conflicto de interés administrador-sociedad", en El gobierno de las sociedades cotizadas, Ed. Marcial Pons, Madrid-Barcelona, 1999, p. 467 y ss.

39 Vid., entre otras, la STS de 21 de mayo de 2001, r. 6463.
} 
del Registro Mercantil, podrá designar a su Presidente, regular su propio funcionamiento, aceptar la dimisión de los Consejeros y designar, en su seno, una Comisión ejecutiva, o uno o más Consejeros delegados, sin perjuicio de los apoderamientos que pueda conferir a cualquier persona.

Asimismo, la representación de la sociedad, en juicio o fuera de él, corresponde a los administradores en la forma determinada por los Estatutos (art. 128 LSA). La falta de regulación estatutaria atinente a este extremo supone la inmediata regulación, por parte del propio Consejo, del régimen de actuación que habrá de guiar el sistema de adjudicación de la representación establecido por el artículo $124.2^{\circ}$ del RRM ${ }^{40}$.

La tendencia doctrinal generalizada, manifestada en referencia a la regulación interna del Consejo de Administración, se muestra partidaria de que sea el propio órgano administrativo el que determine las reglas de la mentada regulación, y no los accionistas a través de la adopción de acuerdos sociales referidos a las temáticas tratadas y reflejadas en las oportunas disposiciones estatutarias ${ }^{41}$.

\section{Códigos Éticos}

La facultad de autoregulación, enunciada en el epígrafe precedente, en modo alguno puede, ello no obstante, quedar exento del establecimiento de reglas de autocontrol, a través de la voluntaria adhesión de la sociedad, a una serie de códigos de conducta y consiguiente vinculación de los miembros del Consejo, a las pautas de actuación fijadas por aquellos.

En este sentido, han sido numerosos los informes suscritos por los distintos países en referencia a las premisas que han de guiar la estructura del Consejo de Administración y los derechos y responsabilidades de los administradores en sus relaciones con los accionistas.

El informe pionero fue el "Code of best Practice", emanado del Comité Cadbury ${ }^{42}$ y creado a sugerencia de la Bolsa de Londres, del Banco de Inglaterra, de las instituciones de ahorro colectivo y de las organizaciones patronales.

40 Para un estudio detallado, se remite al lector a los trabajos de Aranguren Urriza, F. J. y FernándeZ-Tresguerres García, A.F.: "La representación de la Sociedad Anónima", en Estudios sobre la Sociedad Anónima, Ed. Civitas, Madrid, 1991, pp. 159 a 257, y Esteban Velasco, G.: "Modalidades de atribución y ejercicio del poder de representación", en Derecho mercantil de la Comunidad Económica Europea. Estudios en bomenaje a José Girón Tena, Civitas, $1^{\text {A }}$ ed., Madrid, 1991, pp. 303 a 23.

41 JIMÉnEz DE PARGA, R.: "Reglamentación interna de los Consejos de Administración", RDBB N69, enero-marzo 1998, p. 131.

42 Para un análisis comparativo del informe Cadbury y la práctica societaria española, se remite al lector al estudio de SAN SEBASTIÁN, F.: "El informe Cadbury y el Derecho Societario español", RDBB No 53, enero-marzo, 1994, p. 267 y ss. 
Con posterioridad, viene a complementar el anterior código ético, el informe "Greenbury", procedente de la Universidad de Stanford, que centra fundamentalmente su atención en la discrecionalidad atribuida a los órganos de gobierno en orden al régimen de remuneración de los administradores.

Asimismo, merecedores de especial mención lo son, entre otros, el informe norteamericano atinente a los Principles of Corporate Governance: Analysis and recomendations del American Law Institute, el canadiense informe Dey, el informe Vienot realizado por el Comité redactor del Consejo Nacional de la patronal francesa y por la Asociación francesa de empresas privadas y un estudio colectivo realizado por la italiana Università L. Bocconi.

En el ámbito español, en octubre de 1995, el Círculo de empresarios publicó unas "Reflexiones sobre la reforma de los Consejos de Administración" y un año más tarde, en octubre de 1996, a través de un segundo documento titulado "Una propuesta de normas para un mejor funcionamiento de los Consejos de Administración", previa especificación de la independencia facultativa de las sociedades en la elaboración del contenido de sus propios Estatutos de consejeros, concretó las sugerencias establecidas por el primero.

Las notas primordiales del análisis científico, a que nos hemos referido, desarrollan el deber de diligencia de los administradores, fundamentalmente en la vertiente referida a la defensa del interés general de la sociedad, en cuanto interés de todos los accionistas, por encima de intereses particulares propios, que debe orientar la conducta de los administradores, en todo tipo de actuaciones, así como la dedicación plena y atención necesaria, a través de la asistencia a todas las reuniones a las que aquellos son convocados y disposición de la información adecuada para fundamentar sus opiniones, propuestas y modificaciones.

Asimismo, se creó, a instancia de la Comisión Nacional del Mercado de Valores, una Comisión Especial para el estudio de un Código Ético de los Consejeros de Administración de las sociedades, por acuerdo del Consejo de Ministros de 28 de febrero de 1997 y, por Orden del Ministerio de Economía y Hacienda de 24 de marzo del mismo año, fueron designados los componentes que integraron la misma, bajo la presidencia y coordinación del profesor Olivencia. El informe fue presentado el 26 de febrero de 1998, bajo el título "El gobierno de las Sociedades" 43 .

A diferencia de los informes del Círculo de empresarios, en los que se desarrollan las premisas fundamentales que han de guiar la conducta de los administradores, en el deber de lealtad o fidelidad a ellos impuesto, el Informe Olivencia centra fundamentalmente su atención en el alcance del

El Informe Olivencia puede ser consultado, por el lector, en "Informe Olivencia: Recomendaciones sobre un código de buen gobierno para las sociedades", RGD N 646-647. julio-agosto, 1998 , pp. 9.373 a 9.375. 
deber de diligencia, concretado fundamentalmente en los deberes de información, participación, vigilancia e investigación.

Cierto sector doctrinal ha mostrado el desencanto subyacente en el Informe Olivencia, ante el fracaso resultante de la aplicación práctica del principio democrático en el ámbito de las sociedades capitalistas que otorgan el poder soberano a las Juntas Generales ${ }^{44}$, así como el necesario refuerzo que precisa la intervención de la figura del Letrado Asesor, en la adopción de acuerdos de los órganos de administración, mediante la atribución de funciones de absoluta trascendencia para la transparencia de su actuación en este sentido, como lo serían la emisión de un informe sobre la legalidad de los acuerdos y la constancia en los libros de actas de la sociedad y en las certificaciones que se expidan de dichos acuerdos, de la fehaciencia de la oportuna intervención ${ }^{45}$.

El Reglamento tipo del Consejo de Administración, ajustado al Código de Buen Comercio y elaborado por la Comisión Nacional del Mercado de Valores, igualmente integra, entre los deberes de los consejeros, la orientación y control de la gestión y evaluación de los directivos, con el fin de maximizar el valor de los beneficios de la sociedad en favor de los accionistas (art. $30.1^{\circ}$ ), así como el deber de obrar, en el desempeño de estas funciones, con la diligencia de un ordenado empresario y de un representante leal (art. $30.2^{\circ}$ ).

La armonización comunitaria en el ámbito de la estructura de las sociedades anónimas, así como en la delimitación de los poderes y obligaciones atribuibles a sus órganos, pese a la propuesta de la $5^{\text {a }}$ Directiva, formulada en 1972 y modificada en 1983, no ha sido alcanzada.

El sistema de autorregulación propuesto por los Informes, con el objetivo primordial de mejorar el gobierno de las grandes sociedades, responde, fundamentalmente, a las premisas que a continuación se sintetizan.

El poder soberano de la Junta habrá de ceder en favor del órgano de administración, puesto que la atención prioritaria al interés de los accionistas, individualmente considerados, no debe consentir la distorsión o desplazamiento de la concepción institucional de la sociedad.

En este sentido, se precisa la potenciación del Consejo de administración, así como el reforzamiento de las funciones de vigilancia, control, direc-

44 SANChez CAlero, F.: "El Gobierno de las Sociedades cotizadas y su control", RDBB N 65, enero-marzo 1997, p. 226; Rodríguez ArTigas, F.: por su parte, ha hecho, recientemente, mención de tres discrepancias de fondo y método: la concepción del interés social, el modelo de órgano administrativo y la forma de realizar sus reformas, respecto de cuya posible mejora se remice al lector a "Diez años de reforma de las sociedades de capital. Notas sobre el órgano de administración de la sociedad anónima", Libro Homenaje a Ildefonso Sánchez Mera, vol. II, Colegio Notarial de La Coruña (Colegios Notariales de España), Consejo General del Notariado, Madrid, 2002, pp. 1361 y ss.

is Alvarez-Valdés y Valdés, M.: "El Gobierno de las Sociedades: El Informe Olivencia. Secretarios y Letrados Asesores de los órganos de administración", RDBB N" 69, eneromarzo 1998 , p. 259 y ss. 
ción y gestión, asumidas por los distintos miembros que lo integran, los cuales serán requeridos, al efecto de la emisión de valoraciones concretas, y no al de mero asentimiento a las propuestas surgidas en el grupo del que forman parte.

El número de consejeros habrá de ser necesariamente reducido, puesto que lo contrario perjudica seriamente la deliberación de los acuerdos que hayan de ser adoptados, a través del cómputo mayoritario de la emisión consciente de votos favorables.

Los miembros integrantes del Consejo responderán a las expectativas profesionales del perfil característico de la triple denominación que sigue: ejecutivos, profesionales seleccionados por los inversores institucionales e independientes.

Con independencia de la Comisión Ejecutiva, tres comités constituidos en su gran mayoría por consejeros no ejecutivos, conformarán parte importante del ámbito de actuación del propio Consejo, estos son el de auditoría, el de nombramiento de consejeros y altos directivos y el de remuneraciones.

A pesar de la plausible modificación propuesta, el nivel de aceptación del Código ético de buen gobierno, por parte de las empresas españolas, no es satisfactorio, según se desprende de un estudio actualizado a septiembre de 1999 y ello, fundamentalmente, como consecuencia del recelo a la incorporación de directivos ejecutivos externos y al protagonismo de los gestores sobre los propios administradores ${ }^{46}$.

$\mathrm{Si}$ bien las recomendaciones de la Comisión Olivencia no aspiraron, en principio, a tomar cuerpo legal, sino a convertirse en unos principios admonitivos de discrecional aplicación por las sociedades y empresas, el Congreso de los Diputados aprobó, en diciembre de 1999, una moción, por la que se instaba al Gobierno para que convirtiera en normas jurídicas vinculantes estas recomendaciones.

La regulación de los deberes de los administradores, establecida en el Código ético, no prevé la imposición de sanciones para el caso de su no debida observancia o manifiesto incumplimiento.

\section{EL ACUERDO DE RENUNCIA O TRANSACCIÓN DEL EJERCICIO DE UNA ACCIÓN SOCIAL DE RESPONSABILIDAD FRENTE A LOS ADMINISTRA- DORES Y OPOSICIÓN}

Una vez constatada la validez formal del acuerdo en el que se adopte, por mayoría, la decisión de entablar, en nombre de la sociedad, una acción

\footnotetext{
46 Tan solo ha sido incorporado por 80 de las empresas que cotizan en el mercado continuo y por 29 de las que integran el Ibex-35, que como sabemos es la denominación de las 35 sociedades más líquidas del mercado bursátil que sirvieron de modelo, a través de encuestas, al Informe solicitado por el Gobierno; "Conducta empresarial", Editorial del diario ABC de 29 de diciembre de 1999, pág. 11.
} 
social de responsabilidad contra los administradores, aunque no hubiese constado en el orden del día, la deliberación y sometimiento a votación de esta cuestión, los mismos sujetos que acordaron el ejercicio de la acción podrán, posteriormente, mediante la adopción de un ulterior acuerdo, transigir o renunciar a dicho ejercicio.

La LSA, en el primer inciso del segundo apartado del artículo 134, establece que la Junta General, en cualquier momento, podrá transigir o renunciar al ejercicio de la acción, siempre que no se opusiesen a ello socios que representen el cinco por ciento del capital social.

La adopción de esta medida de protección de la minoría, establecida por la Ley, como un mecanismo de vigilancia y control, por parte del accionista o grupo de ellos que alcancen el indicado porcentaje, sobre la actuación de los administradores que se encuentren respaldados por los accionistas mayoritarios, es ciertamente plausible, puesto que si la acción de responsabilidad entablada por la sociedad, ante el eventual fraude de los miembros de los órganos de administración, dependiese con exclusividad, de la mayoría de socios, nos encontraríamos ante relaciones de interdependencia recíproca, que darían lugar, merced a la personalidad encubierta de los administradores, a situaciones de posible fraude.

Ahora bien, la dicción del precepto analizado no esclarece la forma en la que la minoría accionarial indicada habrá de mostrar su desacuerdo, para con el acuerdo social en el que se transige o renuncia al ejercicio de la acción social de responsabilidad.

Un sector autorizado de nuestra doctrina ${ }^{47}$ entiende la facultad de vetar el acuerdo social, adoptado por la mayoría de los socios presentes o representados en la Junta, como un derecho que corresponde tan solo a los socios con derecho de voto y, por tanto, a través de una nueva votación en la que se alcance la radical solución de oposición a la eventual renuncia o transacción, respecto del anterior acuerdo de ejercicio de la acción de responsabilidad.

Por el contrario, un segundo sector ${ }^{48}$, ciertamente minoritario, es partidario de integrar en el cómputo de los socios que sean titulares, cuando menos, del cinco por ciento del capital social, a los accionistas sin voto y por consiguiente, de conceder validez a la oposición formal, frente a la renuncia o transacción del acuerdo en el que se aprueba el ejercicio de la acción, sin que para alcanzar la referida solución, sea preciso un sometimiento a votación respecto al mencionado acuerdo.

\footnotetext{
47 MENÉndez MENÉndez, A. y Beltrán SÁnCHez, E.: "Las acciones sin voto. Comentario a los artículos 90 a 92 del Texto refundido de la Ley de Sociedades Anónimas", RDM N ${ }^{\circ}$ 191, enero-marzo, 1989, p. 397.

48 Rodriguez DE Villa, D.: Impugnación de acuerdos de las Juntas de accionistas, Ed. Aranzadi, Pamplona, $2^{a}$ ed., 1994, p. 150; Martínez Machuca, P. "La oposición al acuerdo de transigir o renunciar al ejercicio de la acción social de responsabilidad", RDM N ${ }^{\circ} 225$, 1997, p. 1176.
} 
La asunción, por parte de los accionistas, de una decisión tan determinante en la vida de la sociedad, como lo es la relativa a la oposición a la renuncia o transacción del ejercicio de una acción social de responsabilidad, frente a los administradores, no debe quedar expresada, a nuestro juicio, en una mera oposición formal con la sola constancia del acta de la Junta General en la que se debatió la cuestión expresada sino que, por el contrario, debe ser sometida a deliberación y subsiguiente votación, sea en la propia Junta en la que se aprobó el acuerdo precedente, sea en una ulterior Junta puesto que, al fin y a la postre, la decisión definitivamente alcanzada habrá de revestir los caracteres que individualizan a los acuerdos sociales y no las decisiones unilateralmente manifestadas.

Al igual que sucede con el acuerdo en el que se aprueba la decisión relativa al ejercicio de la acción social de responsabilidad, y aunque la Ley omita toda consideración al respecto, parece razonable entender que no deviene preceptiva, la previa mención en el orden del día, del sometimiento a deliberación y votación del acuerdo de transigir o renunciar al ejercicio de la acción, puesto que resultaría contener una muy gruesa contradicción, la exigibilidad formal referida respecto a un acuerdo que depende de otro anterior, al que en modo alguno y por expresa indicación legal, le resulta obligatorio el reseñado requisito de validez formal.

\section{BIBLIOGRAFÍA}

- AbBadessa, P.: "Gli organi di gestioni nella Società per azioni: riflessioni critiche", en Il diritto delle società per azioni: problemi, esperien$z a$, progetti a cura di Pietro ABBADESSA e Angel Rojo, Dott. A. Giuffrè Editore, Milano, 1993.

- Alcalá Díaz, M. A.: "Acción individual de responsabilidad frente a los administradores", en Revista de Sociedades No 1, 1993.

- Alcalá Díaz, M. A.: "El deber de fidelidad de los administradores: el conflicto de interés administrador-sociedad", en El gobierno de las sociedades cotizadas, Ed. Marcial Pons, Madrid-Barcelona, 1999.

- Alonso Ureba, A.: "Presupuestos de la responsabilidad social de los administradores de una Sociedad Anónima", en Revista de Derecho Mercantil $\mathrm{N}^{\circ} 198,1992$.

- Alvarez-Valdés y Valdés, M.: "El Gobierno de las Sociedades: El Informe Olivencia. Secretarios y Letrados Asesores de los órganos de administración", en Revista de Derecho Bancario y Bursátil $\mathrm{N}^{\circ} 69$, enero-marzo 1998.

- Aranguren Urriza, F, J.; y Fernández-Tresguerres García, A. F.: "La representación de la Sociedad Anónima", en Estudios sobre la Sociedad Anónima, Ed. Civitas, Madrid, 1991. 
- Bercovitz Rodríguez-CANO, A.: "Régimen general de la responsabilidad civil de los administradores de las sociedades de capital", en La responsabilidad de los administradores de las sociedades de capital. Aspectos civiles, penales y fiscales, Tecnos, Madrid, 1999.

- BolÁs Alfonso, J.: "La adaptación de las sociedades de capital a la vigente normativa: la triple vertiente de la obligación de adaptación. Problemas prácticos", en Revista Jurídica del Notariado, 1992.

- Bueyo díez Jalón, M.; Collado lugo, A.; y Palomo Balda, E.: Responsabilidad de los administradores. Levantamiento del velo, Dossier Práctico Francis Lefebvre, Madrid, 2000.

- Calaza López, S.: El proceso de impugnación de acuerdos sociales de sociedades anónimas y cooperativas, Ed. CEURA, Madrid, 2003.

- Calaza López, S.: El proceso de formación de la voluntad social de las sociedades anónimas y cooperativas: vicios de contenido y de procedimiento, Dykinson, Madrid, 2003.

- Di Sabato, F.: Manuale delle società, UTE'T, Torino, 1999.

- Esteban Velasco, G.: "Modalidades de atribución y ejercicio del poder de representación", en Derecho mercantil de la Comunidad Económica Europea. Estudios en bomenaje a José Girón Tena, Civitas, $1^{a}$ ed., Madrid, 1991.

- Ferré Olivé, J.C.: "La administración social fraudulenta (artículo 295 del Código Penal)", en La responsabilidad de los administradores de las sociedades de capital. Aspectos civiles, penales y fiscales, Tecnos, Madrid, 1999.

- FONT RiBAS, A.: "La asegurabilidad de la responsabilidad de los administradores de sociedades", en La responsabilidad de los administradores de las sociedades de capital. Aspectos civiles, penales y fiscales, Tecnos, Madrid, 1999.

- Jiménez De PARGA, R.: "Reglamentación interna de los Consejos de Administración", en Revista de Derecho Bancario y Bursátil N 69, enero-marzo 1998.

- Magro Servet, V.: "La responsabilidad civil de los administradores de sociedades (especial referencia a la prescripción de la acción para exigirles responsabilidad civil)", en Actualidad Civil $\mathrm{N}^{\circ} 48$, diciembre-enero, 1999-2000,

- Marín Correa, J. M.: "La responsabilidad en el ámbito laboral de los administradores de las sociedades", en La responsabilidad de los administradores de sociedades de capital, Estudios de Derecho Judicial $\mathrm{N}^{\circ}$ 24, CGPJ-CGN, Madrid, 2000.

- Martínez Machuca, P.: "La oposición al acuerdo de transigir o renunciar al ejercicio de la acción social de responsabilidad", en Revista de Derecho Mercantil $\mathrm{N}^{\circ}$ 225, 1997.

- Menéndez Menéndez, A. y Beltran SÁnchez, E.: "Las acciones sin voto. Comentario a los artículos 90 a 92 del Texto refundido de 
la Ley de Sociedades Anónimas", en Revista de Derecho Mercantil $\mathrm{N}^{\circ} 191$, enero-marzo, 1989.

- Monje Gil, A.: "Comisión especial para el estudio de un Código ético de los Consejos de Administración de las Sociedades", en "El Gobierno de las Sociedades", en Revista de Derecho Mercantil N ${ }^{\circ} 228$, 1998.

- Preite, F.: "Sull'ammissibilità dell'impugnativa delle deliberazioni del Consiglio di Amministrazione delle Società per azioni", en Rivista di Diritto Civile, 1967, II.

- Pulgar Ezquerra, J.: "El régimen especial de responsabilidad de los administradores de una Sociedad Anónima por incumplimiento de la obligación legal de adaptación estatutaria", en Revista de Sociedades $\mathrm{N}^{\circ} 2,1994$.

- Rodríguez Artigas, F.: "El deber de diligencia", en El Gobierno de las Sociedades Cotizadas, Ed. Marcial Pons, Madrid-Barcelona, 1999.

- Rodríguez Artigas, F.: "Diez años de reforma de las sociedades de capital. Notas sobre el órgano de administración de la sociedad anónima", en Libro Homenaje a Ildefonso Sánchez Mera, vol. II, Colegio Notarial de La Coruña (Colegios Notariales de España), Consejo General del Notariado, Madrid, 2002.

- Rodríguez De Villa, D.: Impugnación de acuerdos de las Juntas de accionistas, Ed. Aranzadi, Pamplona, $2^{\mathrm{a}}$ ed, 1994.

- Rojo, A. y Beltrán, E.: "El capital social mínimo. Consideraciones de política y de técnica legislativas", en Revista de Derecho Mercantil $\mathrm{N}^{\circ} 187-188,1988$.

- San Sebastián, F.: "El informe Cadbury y el Derecho Societario español", en Revista de Derecho Bancario y Bursátil $N^{\circ} 53$, eneromarzo, 1994.

- Sánchez Calero, F.: "El Gobierno de las Sociedades cotizadas y su control", en Revista de Derecho Bancario y Bursátil No 65 , enero-marzo 1997.

- SPADA, P.: "Ĺamministrazione della società per azioni tra interesse sociale ed interesse di grupo", en Rivista di Diritto Civile N $N^{\circ} 35-1$, 1989.

- Tapia Hermida, A.J.: "Los administradores de Sociedades Anónimas que incumplan los deberes que la Ley les impone en orden a procurar la disolución (art. 262.5 LSA), son responsables de la totalidad de las obligaciones sociales de la Compañía", en Revista de Derecho Bancario y Bursátil N $\mathrm{N}^{\circ}$ 68, octubre-diciembre, 1997.

- Velasco San Pedro, L.A.: "La información en el Consejo de Administración: derechos y deberes del Consejo y de los Consejeros", en El gobierno de las sociedades cotizadas, Ed. Marcial Pons, Madrid-Batcelona, 1999. 